\title{
From genome to ecosystem
}

\author{
Takayuki Ohgushi
}

Received: 11 November 2010/ Accepted: 15 November 2010/Published online: 2 December 2010

(C) The Society of Population Ecology and Springer 2010

Perhaps nobody could cogently argue that ecology and evolution could be completely unconnected disciplines. However, despite the prevalence of these two phenomena in nature, the study of the evolution of adaptive traits has largely been performed independently of the study of community/ecosystem properties, and thus evolutionary biology and community ecology have long developed in isolation. Community ecology explores how species interactions form the structure and dynamics of ecological communities in terms of abundance, distribution, and species diversity, but it has ignored community consequences of phenotypic variation and trait evolution. On the other hand, evolutionary biology examines the genetic background of phenotypic variation within a population and relates it to the evolution of adaptive traits, without considering whether the structure and dynamics of ecological communities exert selection for adaptive traits of community members. More recently, there has been increasing appreciation of the interplay of ecology and evolution in a community context (Johnson and Stinchcombe 2007; Fussmann et al. 2007; Wade 2007; Urban et al. 2008; Post and Palkovacs 2009; Beckerman et al. 2010), and a new research field has rapidly developed that synthesizes ecological communities and trait evolution, represented by community/ecosystem genetics (Whitham et al. 2006; Schweitzer et al. 2008), eco-evolutionary dynamics (Fussmann et al. 2007; Post and Palkovacs 2009), diffuse selection (Strauss et al. 2005), and the geographic mosaic of coevolution (Thompson 2005). For example, by searching for the causality linking genome to

T. Ohgushi $(\bowtie)$

Center for Ecological Research, Kyoto University,

2-Hirano, Otsu, Shiga 520-2113, Japan

e-mail: ohgushi@ecology.kyoto-u.ac.jp ecosystem, community and ecosystem genetics show that genotypes and genotypic variations of foundation species (such as dominant plant species) are of primary importance in the structure of local communities and the regulation of ecosystem processes (Whitham et al. 2008). Also, the genotypic diversity enhances the species richnesses of higher trophic levels and ecosystem functioning such as productivity and pollination service (Crutsinger et al. 2006; Genung et al. 2010). In addition to the genotypic variation, another source of adaptive traits is phenotypic plasticity. Previous studies on phenotypically plastic responses have mainly examined patterns of expression and their adaptive nature (Fordyce 2006), and therefore the community and ecosystem consequences of phenotypic plasticity in an evolutionary context remain largely unknown. However, ecologists have begun to address how phenotypic plasticity governs patterns and processes of trophic interactions, community organization, ecosystem functioning, and biodiversity (Werner and Peacor 2003; Ohgushi 2005; Schmitz 2008). In particular, plants can modify a wide variety of traits in response to herbivores, and these herbivoreinduced plant phenotypes are ubiquitous and widespread phenomena in terrestrial systems. More recently, studies have clearly illustrated that the phenotypic plasticity of plants can play a critical role in structurally organizing plant-based communities through trait-mediated indirect effects (Ohgushi et al. 2007), and that at the same time they can impose selection for adaptive traits of community members (Utsumi et al. 2009).

This special feature is composed of four papers that were derived from presentations at a 2009 Society of Population Ecology symposium in Kyoto. The aim of this Special Feature is to highlight how genetic and phenotypic variations within a population determine community structure and ecosystem functioning, and how higher 
orders of organization (community or ecosystem) drive trait evolution. This new view will provide a framework for developing research to bridge the gap between evolutionary biology and community/ecosystem ecology. Bailey (2010) introduces key concepts of community and ecosystem genetics, and poses the question of why we should consider evolutionary processes in ecological studies. He shows that community genetics integrates ecological interactions and evolutionary processes. Because there can be a genetic basis to community- and ecosystem-level processes, evolutionary processes which alter standing genetic variation can have extended consequences that influence patterns of biodiversity and ecosystem function that exist on the landscape. He also emphasizes the importance of incorporating abiotic variation into community genetic studies, such as the effects of genotypic diversity along an abiotic gradient, affecting diversity in the landscape. Johnson (2010) integrates the ecology, evolution and genetics of species interactions using the common evening primrose and its herbivorous insects. He illustrates that genetic variation and evolution within populations can have cascading effects throughout communities. At the patch level, increasing genotypic diversity leads to greater abundance and diversity of omnivorous and predaceous arthropods. Natural selection on specific plant traits can drive rapid ecological changes in these community variables. Plant genotype affects the preferences and performances of individual arthropod populations, as well as the composition, biomass, total abundance and diversity of arthropod species on plants. Also, he reviews several multifactorial experiments, showing that plant genotype explains much of the variation in community variables. Focusing on eco-evolutionary dynamics in herbivorous insect communities mediated by induced plant responses, Utsumi (2010) specifically addresses the key role of herbivore-induced plant responses in eco-evolutionary dynamics. He highlights the evolution of herbivore traits relevant to plant induction mediated by induced plant responses in a community context, and proposes a hypothetical model that induced plant responses promote ecoevolutionary feedback in herbivore communities. He also argues that the application of the indirect interaction web approach to studies on eco-evolutionary dynamics will provide profound insights into the mechanisms responsible for the maintenance and creation of biodiversity. Schweitzer et al. (2010) explore the potential role of plant genetic variation in plant-soil linkages, utilizing a model system and stands of trees with known gene diversity. They examine effects of forest stand gene diversity on the composition and function of soil microbial communities, and propose a hypothesis that average stand gene diversity influences soil microbial community composition, exoenzyme activity, and soil nutrient pools. They show significant unimodal patterns relating gene diversity to soil microbial community composition, the microbial exoenzyme activity of a carbon-acquiring enzyme, and the availability of soil nitrogen. This pattern is due to the correlation between gene diversity, plant secondary chemistry, and the composition of the microbial community that impacts the availability of soil nitrogen. Stand gene diversity may affect soil microbial communities and soil processes in similar ways to species diversity.

The authors of this Special Feature each take a different creative approach to understanding the link between evolution and community/ecosystem, and propose new hypotheses that will greatly promote this rapidly developing research field. Also, the diversity of approaches can be applied profitably to the study of the variation of adaptive phenotypes based on genotypic variation and phenotypic plasticity, as well as their interactions. We will illustrate the areas that represent the most exciting recent ecological and evolutionary advances, and draw attention to questions that are still largely unexplored in an effort to inspire future research. I hope that this Special Feature will provide readers with a useful overview of this emerging field by sparking awareness of and fostering discussion on the integration of the long-isolated disciplines: evolutionary biology and community/ecosystem ecology.

Acknowledgments The 2009 Society of Population Ecology symposium was partly supported by Kyoto University Global COE Program (A06).

\section{References}

Bailey JK (2010) From genes to ecosystems: a genetic basis to ecosystem services. Popul Ecol 53. doi:10.1007/s10144-0100251-4

Beckerman AP, Petchey OL, Morin PJ (2010) Adaptive foragers and community ecology: linking individuals to communities and ecosystems. Funct Ecol 24:1-6

Crutsinger GM, Collins MD, Fordyce JA, Gompert Z, Nice CC, Sanders NJ (2006) Plant genotypic diversity predicts community structure and governs an ecosystem process. Science 313:966968

Fordyce JA (2006) The evolutionary consequences of ecological interactions mediated through phenotypic plasticity. J Exp Biol 209:2377-2383

Fussmann GF, Loreau M, Abrams PA (2007) Eco-evolutionary dynamics of communities and ecosystems. Funct Ecol 21:465-477

Genung MA, Lessard J-P, Brown CB, Bunn WA, Cregger MA, Reynolds WN, Felker-Quinn E, Stevenson ML, Hartley AS, Crutsinger GM, Schweitzer JA, Bailey JK (2010) Non-additive effects of genotypic diversity increase flora abundance and abundance of floral visitors. PLoS ONE 5:1-7

Johnson MTJ (2010) The contribution of evening primrose (Oenothera biennis) to a modern synthesis of evolutionary ecology. Popul Ecol 53. doi:10.1007/s10144-010-0250-5

Johnson MTJ, Stinchcombe JR (2007) An emerging synthesis between community ecology and evolutionary biology. Trends Ecol Evol 22:250-257 
Ohgushi T (2005) Indirect interaction webs: herbivore-induced effects through trait change in plants. Annu Rev Ecol Evol Syst 36:81-105

Ohgushi T, Craig TP, Price PW (2007) Ecological communities: plant mediation in indirect interaction webs. Cambridge University Press, Cambridge

Post MD, Palkovacs EP (2009) Eco-evolutionary feedbacks in community and ecosystem ecology: interactions between the ecological theatre and the evolutionary play. Phil Tran R Soc B 364:1629-1640

Schmitz OJ (2008) Effects of predator hunting mode on grassland ecosystem function. Science 319:952-954

Schweitzer JA, Madritch MD, Bailey JK, LeRoy CJ, Fischer DG, Rehill BJ, Lindroth RL, Hagerman AE, Wooley SC, Hart SC, Whitham TG (2008) From genes to ecosystems: the genetic basis of condensed tannins and their role in nutrient regulation in a Populus model system. Ecosystems 11:1005-1020

Schweitzer JA, Fischer DG, Rehill BJ, Wooley SC, Woolbright SA, Lindroth RL, Whitham TG, Zak DR, Hart SC (2010) Forest gene diversity is correlated with the composition and function of soil microbial communities. Popul Ecol 53. doi:10.1007/s10144010-0252-3

Strauss SY, Sahli H, Conner JK (2005) Toward a more trait-centered approach to diffuse (co)evolution. New Phytol 165:81-90

Thompson JN (2005) The geographic mosaic of coevolution. The University of Chicago Press, Chicago
Urban MC, Leibold MA, Amarasekare P, De Meester L, Gomulkiewicz R, Hochberg ME, Klausmeier CA, Loeuille N, de Mazancourt C, Norberg J, Pantel JH, Strauss SY, Vellend M, Wade MJ (2008) The evolutionary ecology of metacommunities. Trends Ecol Evol 23:311-317

Utsumi S (2010) Eco-evolutionary dynamics in herbivorous insect communities mediated by induced plant responses. Popul Ecol 53. doi:10.1007/s10144-010-0253-2

Utsumi S, Ando Y, Ohgushi T (2009) Evolution of feeding preference in a leaf beetle: the importance of phenotypic plasticity of a host plant. Ecol Lett 12:920-929

Wade MJ (2007) The co-evolutionary genetics of ecological communities. Nat Rev Genet 8:185-195

Werner EE, Peacor SD (2003) A review of trait-mediated indirect interactions in ecological communities. Ecology 84:1083-1100

Whitham TG, Bailey JK, Schweitzer JA, Shuster SM, Bangert RK, LeRoy CJ, Lonsdorf EV, Allan GJ, DiFazio SP, Potts BM, Fischer DG, Gehring CA, Lindroth RL, Marks JC, Hart SC, Wimp GM, Wooley SC (2006) A framework for community and ecosystem genetics: from genes to ecosystems. Nat Rev Genet 7:510-523

Whitham TG, DiFazio SP, Schweitzer JA, Shuster SM, Allan GJ, Bailey JK, Woolbright SA (2008) Extending genomics to natural communities and ecosystems. Science 320:492-495 